\title{
A STUDY ON CUSTOMER PREFERENCES AND PERCEPTIONS ON QUALITY AND SERVICES OF READY MIXED CONCRETE AS A SUSTAINABLE BUILDING MATERIAL IN BANGALORE CITY, KARNATAKA
}

\author{
L R Manjunatha ${ }^{1}$, Sandya R Anvekar ${ }^{2}$, S Savitha Sagari ${ }^{3}$, Archana Kumarswamy ${ }^{4}$ \\ ${ }^{I}$ PhD Research Scholar, $R \&$ D Centre, Bharatiyar University \\ ${ }^{2}$ Professor, VTU, Bangalore \\ ${ }^{3}$ Student, M. Tech, Department of Civil Engineering, BMSCE, Bangalore \\ ${ }^{4}$ Student, M. Tech, Department of Civil Engineering, BMSCE, Bangalore
}

\begin{abstract}
This research paper is a study on customer preference and perceptions about the quality and services of Ready Mixed Concrete $(R M C)$ and traditional Site Mixed Concrete (SMC) in Construction Industry in Bengaluru, Karnataka. The market potential of RMC is huge and the perceptions of its customer's viz., builders, contractors, developers and promoters are significant for the growth and promotion of RMC. An analysis was done based on the experience in the construction industry, type of projects handled and economic conditions of the participants. Based on this demographic profiling the responses of the participants was analyzed to draw conclusions.
\end{abstract}

Keywords: Ready Mixed Concrete, Customer Preferences and Perceptions, Sustainability, Quality and Services $* * *$

\section{INTRODUCTION}

Rapid urbanization of Bangalore City has led to the growth of a robust construction industry. Huge investments have been made for the growing population in the form of Flyovers, Metros, Apartments, IT parks, Shopping Malls, Housing, Commercial and Industrial projects, Institutional Projects etc.

Projects of such large magnitudes consume large quantities of concrete. Concrete is the premier construction material in the construction industry around the world. It is a man-made product, mainly consisting of Portland cement and/or secondary cementitious materials (PFA, GGBS, Microsilica, etc), aggregates, water and admixtures. Concrete has a high compressive strength and stiffness, low thermal and electrical conductivity, besides being non-combustible and non-toxic. In India there are two modes of manufacturing of concrete, Site mixing and procuring from Ready Mixed Concrete manufacturers.

As time is directly equivalent to money, especially in the construction industry, there is a great demand for fast track construction which needs sophistication and advanced technology. Ready mixed concrete is an advanced technology, which involves a high degree of mechanization and automation. It is technologically superior to the Site Mixed Concrete. RMC is generally superior in terms of quality, speed, life-cycle cost and eco-friendliness. Owing to these advantages it is slowly replacing Site Mixed Concrete.

The numbers of RMC manufacturers in Bangalore are increasing day by day to cater to the increasing demands of the industry. A number of local RMC manufacturers have thrown their hats in the ring along with national companies such as Ultratech, RMC Readymix (India), ACC, Lafarge, RDC etc.

This research paper is a study on customer perceptions about the quality and services of Ready Mixed Concrete. The study is based on a survey conducted among the customers of concrete, Viz. Architects, Engineers, Contactors and Builders on the brand, quality, supply, growth, durability, market potential of concrete in the city. The analysis was done based on the demographic profile of the respondents The answers given by them were analyzed to draw conclusions that can be used to determine the factors that can potentially be crucial for the marketing strategy for RMC and to improve RMC products and services

As an added advantage quantity of Cement can be reduced in Ready Mixed Concrete by replacing a portion of cement by supplementary cementitious materials like Ground granulated blast furnace slag (GGBS), Flyash, Microsilica etc which replaces Portland cement and makes the concrete sustainable. 


\section{SUSTAINABILITY IN CONSTRUCTION}

The concept of sustainability is based on the premise that people and their communities are made up of social, economic, and environmental systems that are in constant interaction and that must be kept in harmony or balance if the community is to continue to function to the benefit of its inhabitants - now and in the future. Sustainable construction aims at reducing the environmental impact of a building over its entire life span, while optimizing its economic viability and the comfort and safety of its occupants.

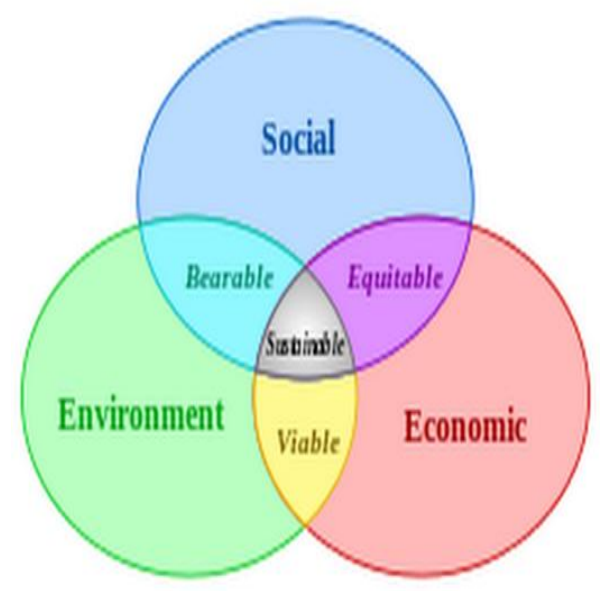

Fig 1: Sustainable Solution is one that is Environment friendly, economic and socially acceptable

This development made with less energy utilization and less wastage helps the well-being of the society and has less impact on the environment.

Sustainable construction involves the use of greener materials and greener technologies. As a nearly inert material, concrete is an ideal medium for recycling waste or industrial byproducts. Many materials that would end up in landfills can be used instead to make concrete. Blast furnace slag, recycled polystyrene, and fly ash are among materials that can be included in the recipe for concrete and further enhance its appeal. Waste products such as scrap tires and kiln dust are used to fuel the manufacture of cement. Even old concrete itself can be reborn as aggregate for new concrete mixtures.

Another environmental plus for concrete is energy efficiency. From manufacture to transport to construction, concrete is modest in its energy needs and generous in its payback. Further commendable characteristics of concrete are waste minimization and long life. Whether it's cast-in-place or precast, concrete is used on an as-needed basis. Leftovers are easily reused or recycled. And concrete is a durable material that actually gains strength over time, conserving resources by reducing maintenance and the need for reconstruction. Ready Mixed Concrete has higher durability as there is better process control and monitoring of raw materials. Addition of supplementary cementitious materials such as fly ash, silica fumes, GGBS reduces perviousness in concrete making it more durable.

In Bangalore most RMC manufacturers replace cement with fly ash and GGBS. The advantages of the two materials are discussed here.

\subsection{Fly Ash}

Fly ash is a fine, glass powder recovered from the gases of burning coal during the production of electricity. These micron-sized earth elements consist primarily of silica, alumina and iron. Using fly ash in concrete has the following advantages: Reduced Shrinkage (The largest contributor to drying shrinkage is water content. The lubricating action of fly ash reduces water content and drying shrinkage), Reduced Heat of Hydration (The pozzolanic reaction between fly ash and lime generates less heat, resulting in reduced thermal cracking when fly ash is used to replace portland cement) and Increased Workability (Concrete is easier to place with less effort, responding better to vibration to fill forms more completely)

\subsection{GGBS}

GGBS is obtained by quenching molten iron slag from a blast furnace in water or steam, to produce a glassy, granular product that is then dried and ground into a fine powder. Replacing the Portland cement by GGBS helps in reducing $\mathrm{CO}_{2}$ emissions and in conserving non-renewable resources of limestone. It reduces heat of hydration and minimization of thermal cracks. GGBS is used to make durable concrete structures residential, commercial and industrial complexes, mass concreting structures like dams, water retaining structures, pre-cast structures, roads, flyovers.

\section{OBJECTIVES OF THE STUDY}

- Determine the perceptions of customers about RMC

- Determine the market potential of RMC in construction industry in Bengaluru city

- Determine the brand preference, expectations and perceptions on quality, cost and services

- Analyze the responses of the customers based on the demographic profiling to determine a target for improving the marketing strategy for RMC companies.

\section{METHODOLOGY}

In the present study, the authors empirically investigated the Customers' perceptions on ready mixed concrete and site mixed concrete. Around 40 customers were contacted and details were collected in a questionnaire format. 
The responses of B2B customers of RMC, viz., Engineers, Project Managers, Contractors, Individual House Builders and Construction Companies who are involved in building various construction projects in and around Bengaluru city, were collected.

Demographic profiling of the respondents was done based on the experience of the respondents in the construction industry, domain of work, major segments of work handled and company turnover.

The type of concrete preferred by the respondents was determined; RMC, SMC or both. Additionally the perception of the customers towards quality, service, cost and punctuality was studied.
The preferences of customers with respect to the brands of concrete used were studied. The use of national versus local brands was studied along with the preference of national brands.

The criteria considered by customers while making a decision on the purchase of concrete such as brand image, price, payment terms, quality and service were studied.

The responses were converted into a binary format to enable analysis. These values were entered in a spread sheet and analysis was carried out.

\section{RESULTS AND DISCUSSIONS}

The demographic profiling of respondents is indicated in Table 1.

Table 1: Demographic Profile of Respondents

\begin{tabular}{|l|l|l|l|l|l|l|l|}
\hline Experience & $\%$ & Domain Area & $\%$ & Major Segments Handled & $\%$ & Company Turnover & $\%$ \\
\hline$<5 \mathrm{y}$ & 37.5 & Architects & 5 & Residential & 35 & $<5 \mathrm{cr}$ & 37.5 \\
\hline $5-10 \mathrm{y}$ & 27.5 & Engineers & 30 & Commercial & 5 & $10-20 \mathrm{cr}$ & 15 \\
\hline $10-15 \mathrm{y}$ & 22.5 & PMC & 22.5 & Both & 40 & $20-50 \mathrm{cr}$ & 12.5 \\
\hline $15-20 \mathrm{y}$ & 7.5 & Contractor & 40 & Industrial & 2.5 & $50-100 \mathrm{cr}$ & 15 \\
\hline$>20$ & 5 & House Owner & 2.5 & Infrastructure and IT & 12.5 & $100-500 \mathrm{cr}$ & 7.5 \\
\hline- & - & - & - & Individual Houses & 12.5 & $>500 \mathrm{cr}$ & \\
& & & & & & 12.5 \\
\hline
\end{tabular}

\subsection{Type of Concrete Used}

Based on the economic conditions and time constraints customers choose either RMC or SMC or both (Chart 1a). Further all companies with turnover greater than 10 crores use $\mathrm{RMC}$, as large projects consume larger quantities of concrete, RMC is procured. Smaller companies and individual house builders are also seen to be procuring RMC, but also use SMC. For large quantities like slabs, beams and footings RMC is used while columns and minor components are built with SMC

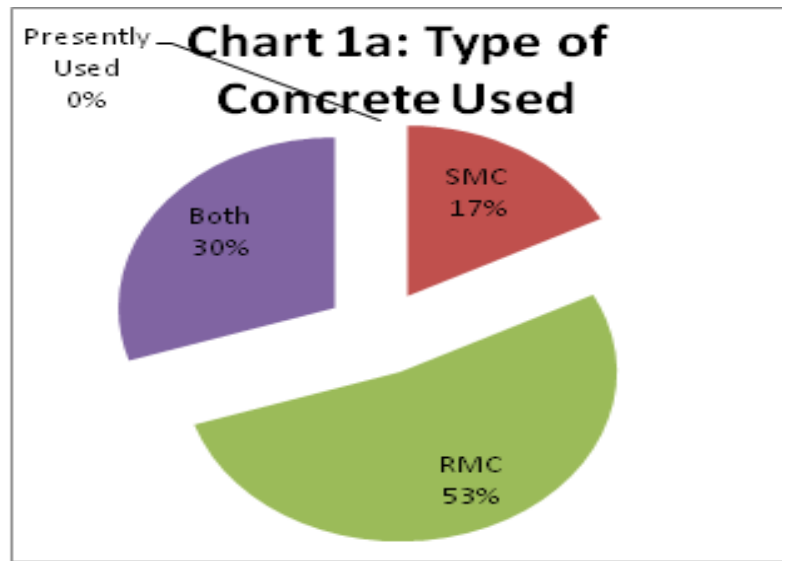

Even though $47 \%$ people use SMC, $72 \%$ people would prefer to use RMC as it is more convenient in terms of time and service (Chart $1 b)$. 


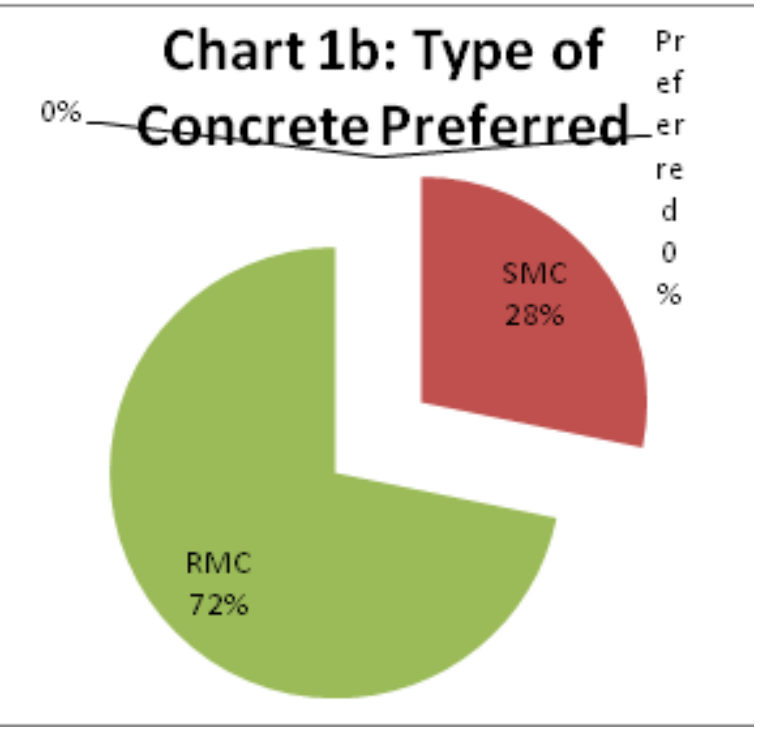

Of the RMC users, $18 \%$ use concrete from their own batching plants and $70 \%$ from only commercial batching plants. The rest procure from commercial plants only when the demand for concrete cannot be met by their own plants. Also it can be seen that all the respondents using concrete from their batching plants are from companies that have a turnover greater than 50 crores.

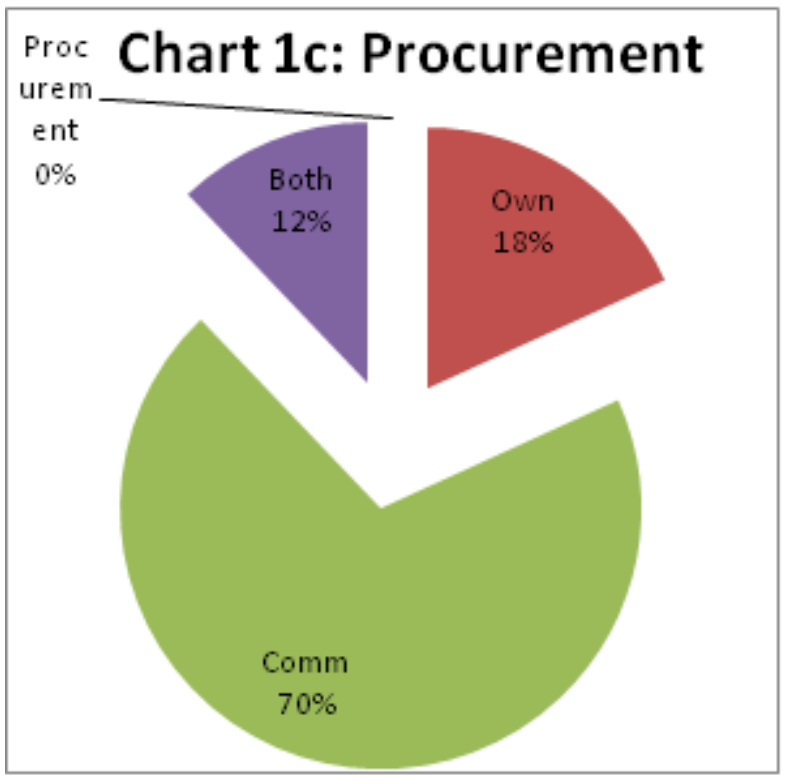

$33 \%$ of the respondents use RMC supplied by local manufacturers while the rest procure from branded suppliers (Chart 1d).

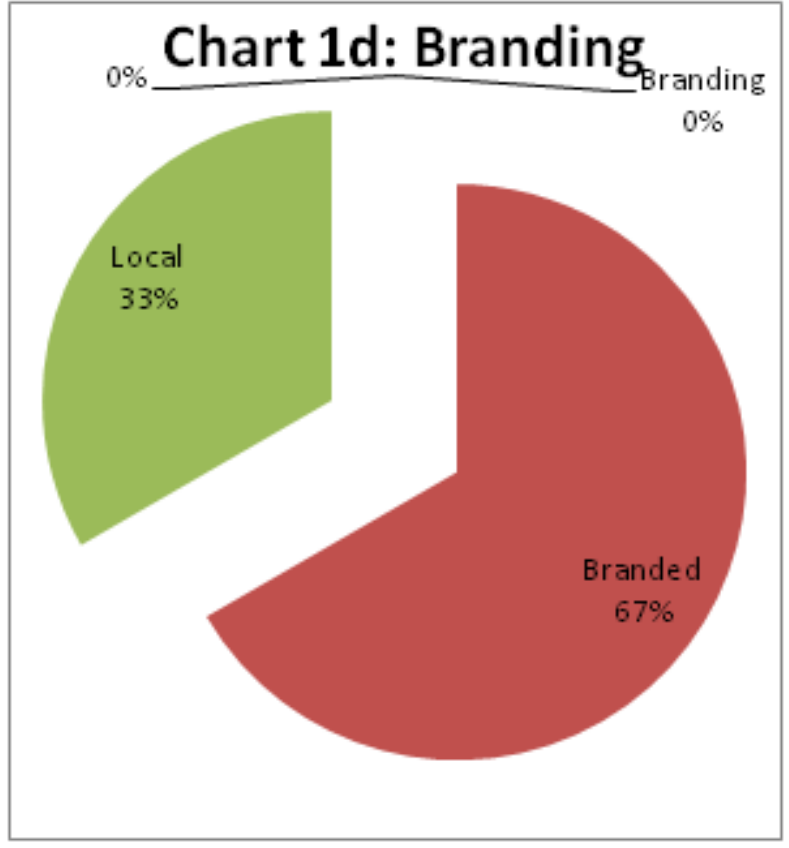

$64 \%$ of the respondents procure from a single supplier, while $27 \%$ from two suppliers and the rest from multiple suppliers.

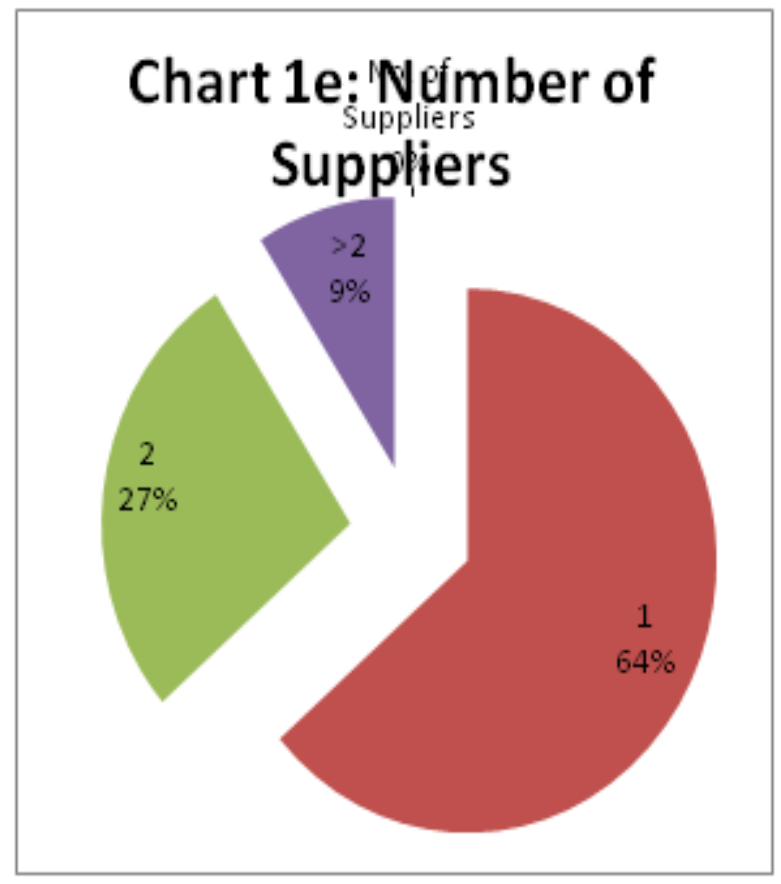

\subsection{Brand Preferences}

Even though $33 \%$ of the respondents procure RMC from local manufacturers, only $10 \%$ are advised by their engineers/architects to procure RMC from branded companies (Chart 2a). 


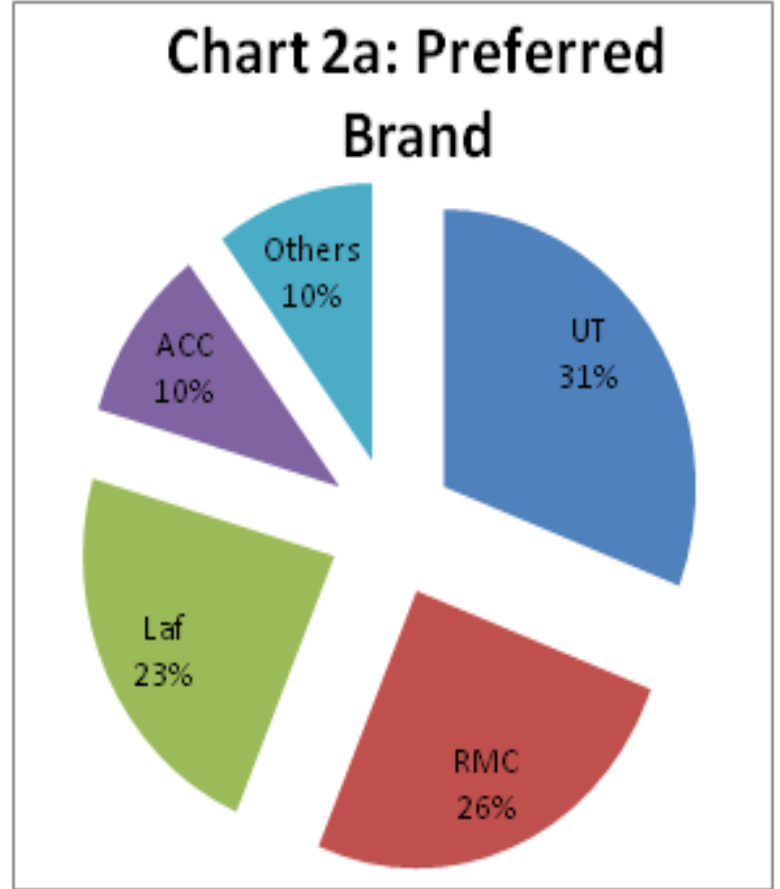

When asked to recommend a RMC supplier based on experience and satisfactory service and quality, most respondents recommend the brand that has been referred to them by their engineer/architect (Chart 2b).

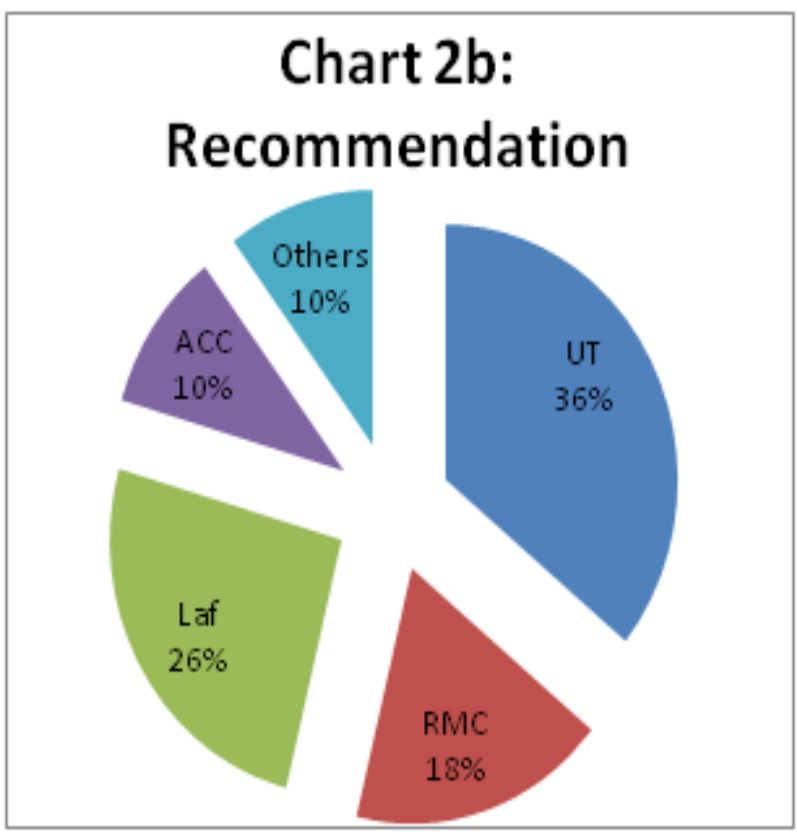

From Charts $2 \mathrm{a}$ and $2 \mathrm{~b}$, it can be seen that Ultratech is the most preferred brand, followed closely by RMC Readymix India, Lafarge and ACC. $10 \%$ of the respondents recommend local brands as well. This goes to show that local suppliers are doing satisfactorily as well.

\subsection{Customer Ratings}

The respondents were asked to rate the quality, services, cost and punctuality of RMC suppliers in the City. The following charts depict the responses given by them.

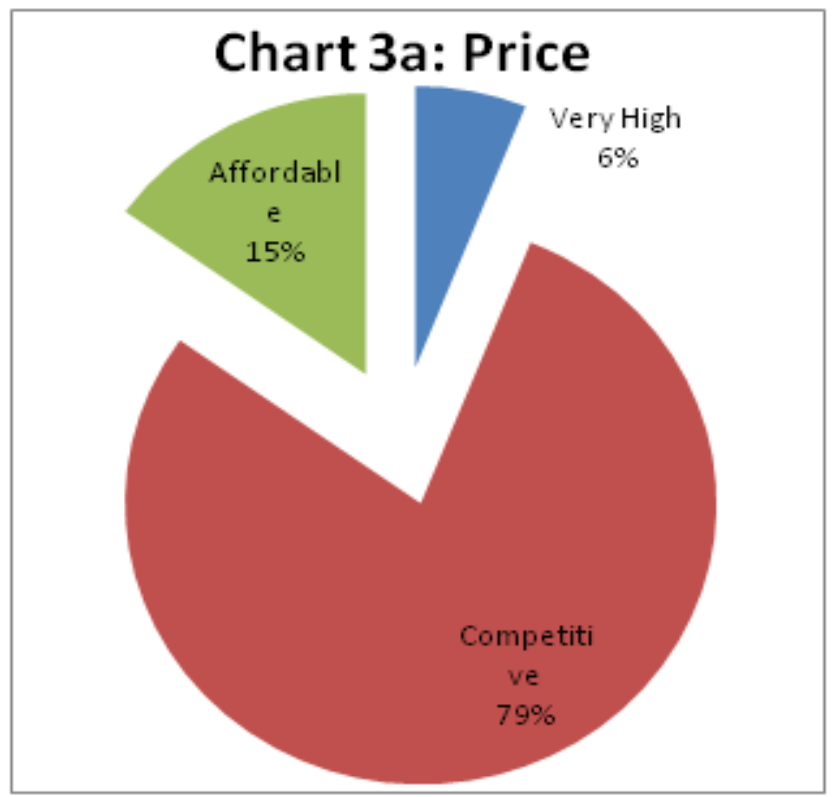

Chart $3 \mathrm{a}$ shows that $79 \%$ of the respondents feel that RMC prices are competitive, while $15 \%$ feel that it is affordable and only $6 \%$ feel it is very high. Hence it can be assumed that the present price is acceptable to most people.

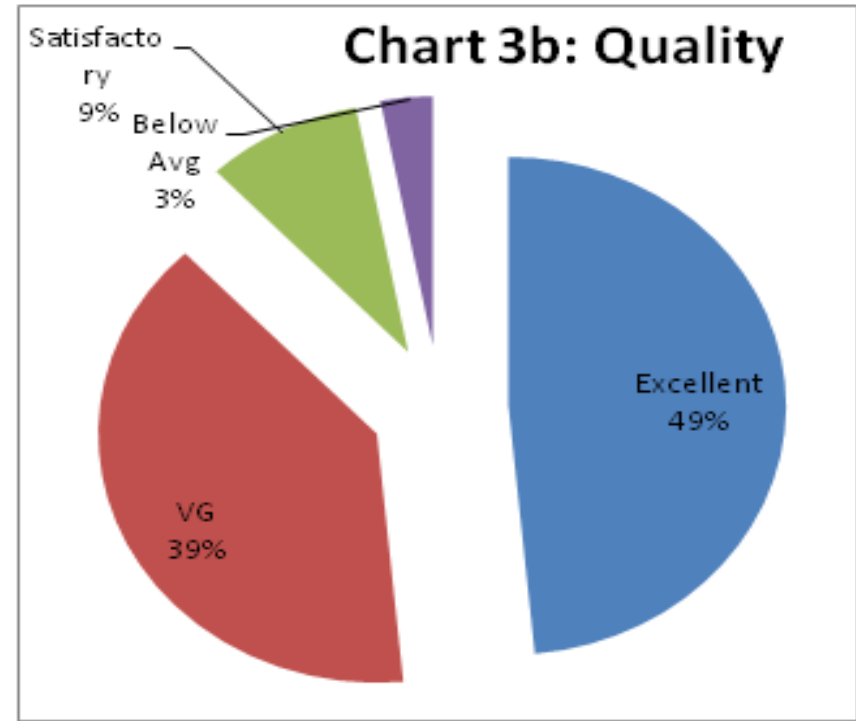

Chart $3 \mathrm{~b}$ shows that $49 \%$ of the respondents find the quality of RMC excellent and $39 \%$ find it very good. This shows that the quality of concrete supplied is found to be acceptable as well 

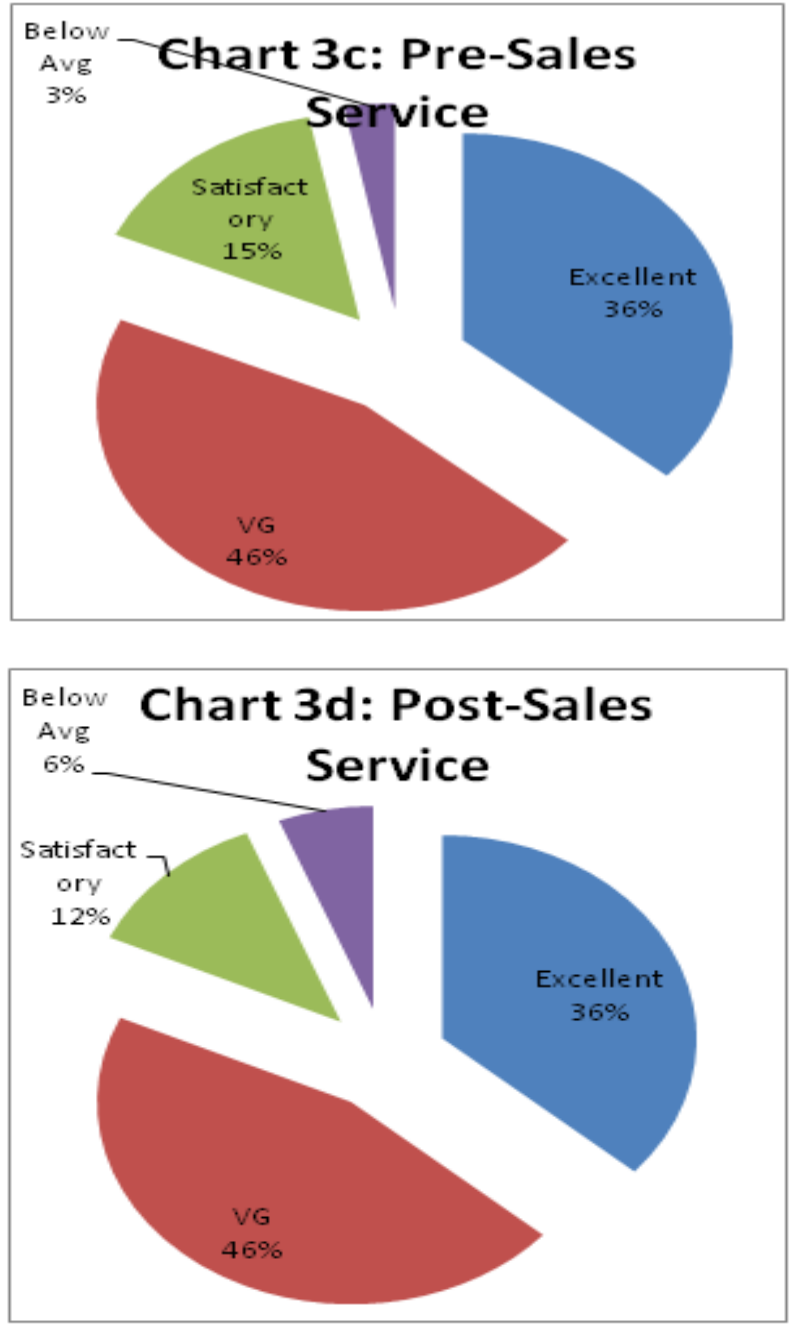

Charts $3 \mathrm{c}$ and $3 \mathrm{~d}$ show that most respondents have said that the pre-sales and post-sales service is acceptable. However, service can be improved, by providing better technical consulting and support as $18 \%$ of respondents feel there is room for improvement here.

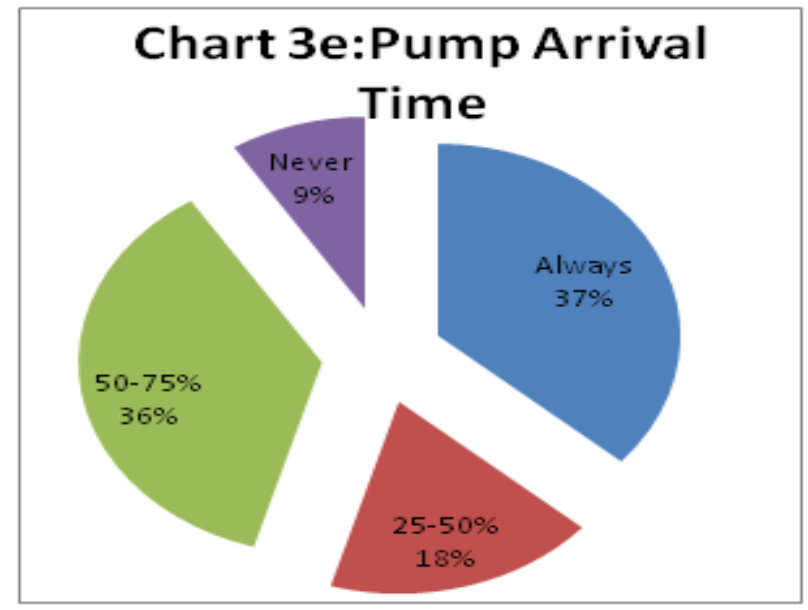

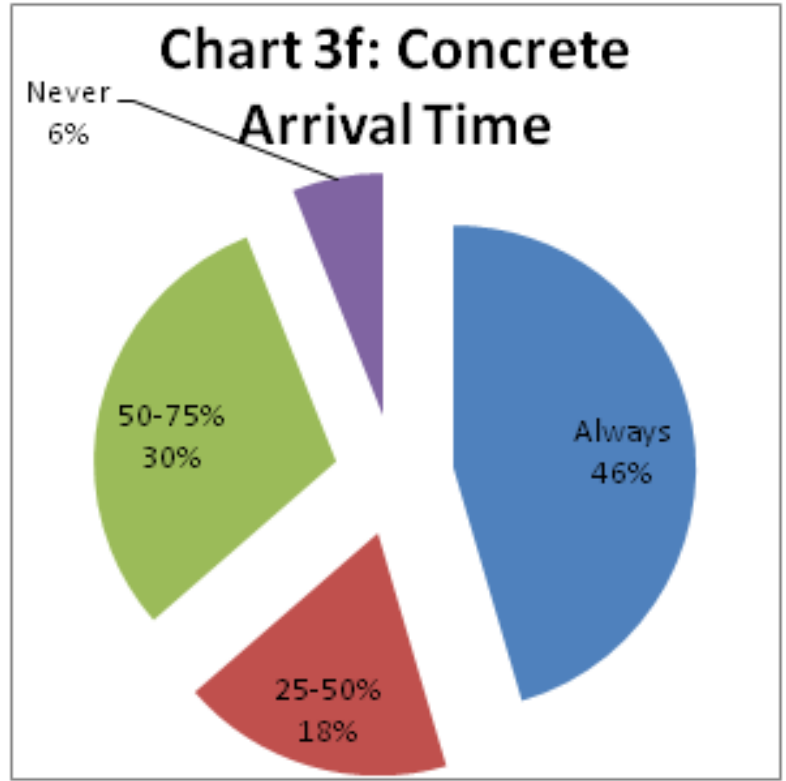

Charts $3 \mathrm{e}$ and $3 \mathrm{f}$ show that punctuality is a concern when it comes to RMC. Most respondents have a repetitive complaint that pumps and transit mixers are not punctual. However, most people attribute this to the curfews on the movement of heavy vehicles during peak traffic. As this aspect is not under the control of RMC suppliers, not much can be done.

\subsection{Decision Criteria}

The respondents were asked to rate the importance of various parameters while making a decision regarding the procurement of RMC from various suppliers. Charts $4 \mathrm{a}-\mathrm{e}$ show the responses given by them.

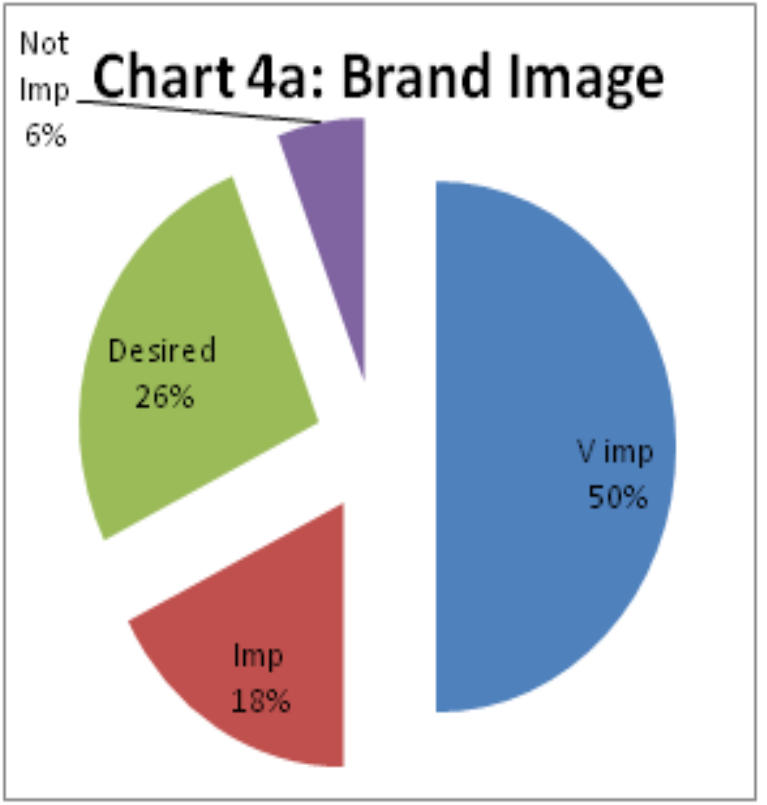


$50 \%$ of the respondents think brand image is very important and $18 \%$ feel that its important. However $26 \%$ feel that it is desired and $6 \%$ feel that it is not important at all. This shows that a brand name is not important to all and as long as the money's worth is delivered; the name on the truck doesn't matter. (Chart 4a)
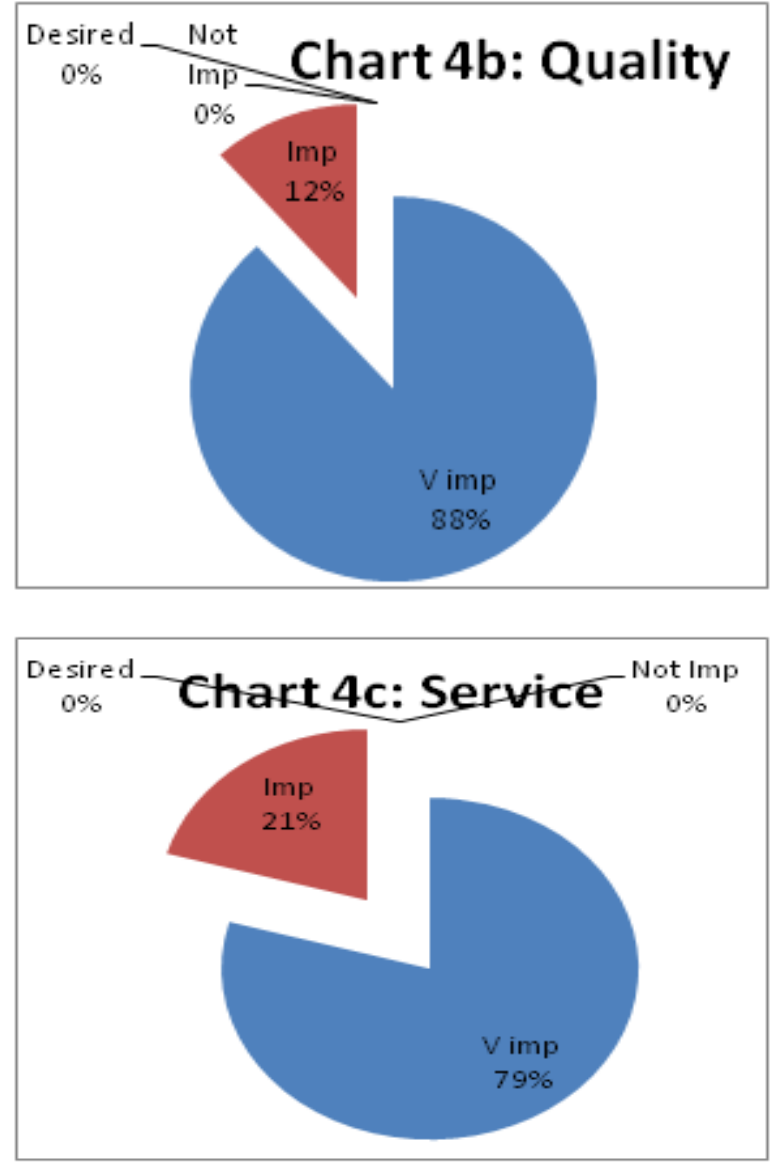

Charts $4 \mathrm{~b}$ and $4 \mathrm{c}$ shows that when quality, service are under question, no one wants to make an error and everyone rates these parameters as very important or important.

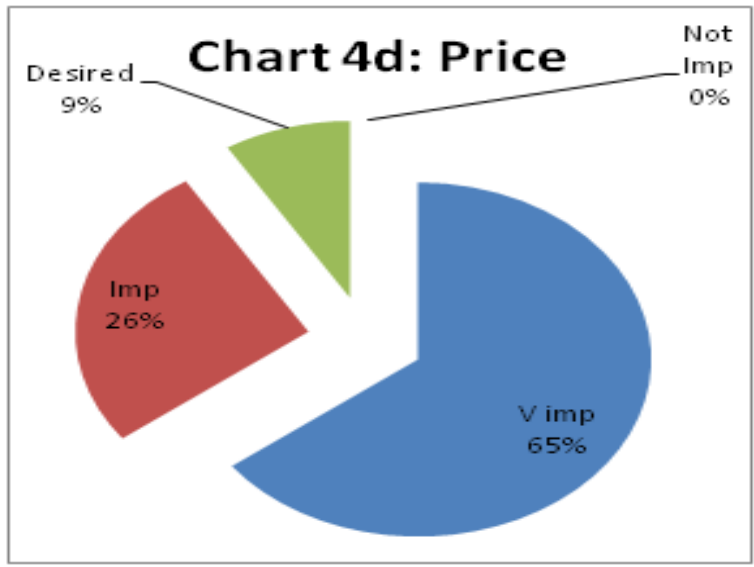

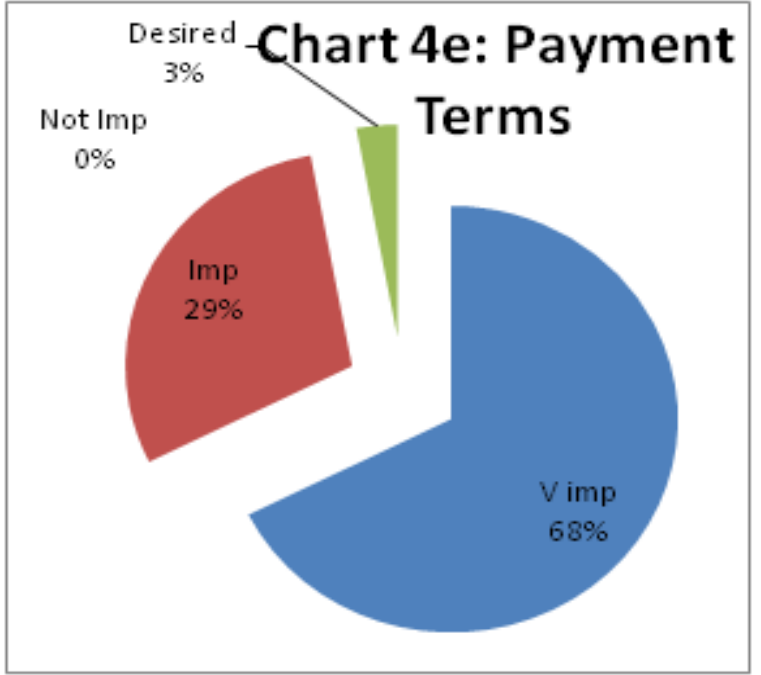

Charts $4 \mathrm{~d}$ and $4 \mathrm{e}$ show that even though low price and convenient payment terms are important, respondents are willing to compromise a little to get better quality and service or brand image

\section{CONCLUSIONS}

Construction industry is one of the fastest growing industries in India. Construction has accounted for around 40 per cent of the development investment during the past 50 years. Labelled as 'the fastest growing city in Asia', Bangalore is one of the cities that have seen this tremendous development. It is expected that by year 2022 the demand for concrete will be 800 million cubic meters. Most of this demand will have to be fulfilled by RMC.

This survey has revealed that most consumers of concrete have accepted RMC as an alternative to SMC.RMC has come as a boon to the construction industry. It has played a pivotal role in changing the landscape of Bengaluru in terms of quality and faster construction of buildings with lesser manpower.

The increased usage of green substitute materials like flyash, GGBS, manufactured sand in manufacturing the Ready Mixed concrete in recent times has led to reduced usage of cement and natural sand. This has made RMC a sustainable alternative to SMC.

Based on the data collected by RMC companies like RMC India, ACC, Ultratech the supplementary cementitious materials (SCMs) are added in the preparation of concrete mix which has good durability and reduced cost.

Based on IS codes cement can be replaced by fly ash up to $35 \%$ and GGBS up to $70 \%$. 
$60 \%$ of the people are not aware of sustainable concrete but the sustainable concrete recipe is made by adding $15-50 \%$ of the supplements based on the grade of concrete.

There is an increased use of fly ash utilization from the up to $60 \%$ for high fly ash content concretes and of GGBS up to $75 \%$.

However, for heavy loaded structures like bridges, flyovers etc., the replacements of cement by supplementary materials are not made.

\section{ACKNOWLEDGEMENTS}

The authors would like to thank all the participants of the survey for their valuable time and suggestions.

\section{REFERENCES}

[1] 'A Study of B2B Customers' Perceptions on Ready Mixed Concrete (RMC) and traditional Site Mixed Concrete (SMC) in Construction Industry in Bengaluru City' by L R Manjunatha, PhD Research Scholar , R \& D Centre,Bharatiyar University and Dr.Sandya $R$ Anvekar Professor, VTU, Bangalore.

[2] The 2012 NRMCA Supplementary Cementitious Materials Use Survey by Karthik H. Obla, Colin L. Lobo, and Haejin Kim National Ready Mixed Concrete Association 900, Spring Street, Silver Spring, MD 20910.

[3] www.wikipedia.org 